\title{
Intercooperação entre cooperativas: barreiras e desafios a serem superados
}

\author{
Intercooperation among cooperatives: barriers and challenges to overcome
}

\begin{abstract}
Resumo
O Cooperativismo é uma forma de união entre indivíduos que tem como finalidade principal a ajuda mutua através do trabalho em conjunto e que possui em sua essência princípios que norteiam seus valores. Um destes princípios é a intercooperação, que é basicamente a cooperação entre cooperativas. Porém devido a fatores diversos, este princípio possui resistência no setor. Portanto o presente estudo tem como finalidade identificar as barreiras e os desafios que impendem maior intercooperação entre as cooperativas. A metodologia aplicada envolve pesquisa exploratória bibliográfica de análise qualitativa com levantamento de casos de intercooperação entre cooperativas e de fatores de resistência a este princípio cooperativista. Com o estudo se vislumbrou a intercooperação como alternativa para o desenvolvimento das cooperativas, contudo entre os principais desafios a serem superados estão às diferenças culturais de cada cooperativa, o medo de perda de autonomia ou de deixar de existir, o individualismo e oportunismo, a falta de formalização de alguns arranjos, a vaidade, a falta de confiança e o excesso de competitividade entre as próprias cooperativas.
\end{abstract}

Palavras chave: Princípio da intercooperação, redes, obstáculos.

\begin{abstract}
The Cooperative is a form of union between individuals whose main purpose is the mutual support by working together and that has core principles that guide their values. One of these principles is the intercooperation, which is basically the cooperation among cooperatives. However due to several factors, this principle has resistance in the sector. Therefore this study aims to identify the barriers and challenges that prevent greater inter-cooperation among cooperatives. The methodology involves bibliographic exploratory research with qualitative analysis by means of survey of cases of intercooperation among cooperatives and about the resistance factors with cooperation principle. The results indicate the cooperation as an alternative to the development of cooperatives, however among the main challenges to be overcome are the cultural differences of each cooperative, fear of loss of autonomy or cease to exist, individualism and opportunism, the lack of formalize some arrangements, vanity, the lack of confidence and strong competition between the cooperatives themselves.
\end{abstract}

Keywords: Cooperation principle, networks, obstacles.

Recebido: 26/11/2015 Aceito: 06/01/2016

Robson Rodrigo Pereira Konzen ${ }^{1}$ e Carlos Alberto Oliveira ${ }^{2}$

${ }^{1}$ Faculdade de Tecnologia do Cooperativismo, MBA em Gestão de Cooperativas- robsonrpk@ hotmail.com- Rua Helberg Ehardt Franke , n⿳o 336, Bairro Cipriano de Oliveira, Vera Cruz, RS, CEP: 96880-000

2 Faculdade de Tecnologia do Cooperativismo, professor de elaboração e análise de projetos -

carlosoliveirafepagro@gmail.com 


\section{Introdução}

$\mathrm{O}$ cooperativismo é um sistema organizado por pessoas, no qual o objetivo principal está na ajuda mútua, em busca de interesses em comum. Para tanto, os participantes destes grupos devem contribuir com bens e serviços para $o$ exercício da atividade econômica, ou seja, os interesses do grupo devem prevalecer sobre os interesses individuais (MENEZES, 2005; CARVALHO, 2011). A cooperação como forma de organização de trabalho pode ser encontrada em todas as formas sociais, modo de produção comunal primitivo, escravista feudal, capitalista e socialista (ZAMBERLAM; FRONCHETI, 1992).

Segundo Ostrom (2000) aqueles dos nossos ancestrais, que resolveram problemas de ação coletiva de forma mais eficaz, e aprenderam a reconhecer quem era enganador e quem era digno de confiança, tinham uma vantagem seletiva sobre aqueles que não percebiam estas diferenças. A importância das ações coletivas é presente na visão de Nowak (2006) que entende a cooperação como o segredo por trás do continuado processo evolucionário. A cooperação prevalece entre muitas espécies, sugerindo que este comportamento é a melhor estratégia de sobrevivência no longo prazo (PENNISI, 2005).

O comportamento cooperativo dos seres humanos se diferencia das demais espécies no aspecto motivacional, pois enquanto as outras espécies cooperam em função do altruísmo genético ou devido às repetidas interações, os humanos cooperam por estes mesmos motivos, somados a sua capacidade linguística e física (SMITH, 2003). Estas capacidades permitem a formulação de normas de conduta social, o surgimento de instituições para regular condutas e a capacidade psicológica de internalizar as normas.

De acordo com os autores, Carvalho (2011); Menezes (2005), após a revolução industrial na Inglaterra um grupo de trabalhadores da classe operária decidiu se unir criando associações de caráter assistencial que pudessem contribuir na ajuda daquele povo que tinha como problema os baixos salários e a longa jornada de trabalho, porém, os trabalhadores não obtiveram êxito. Entretanto, anos depois, com base em antigas experiências, 28 operários na sua maioria tecelões que enfrentavam problemas sociais se reuniram para ponderar suas ideias, respeitando seus costumes, tradições e estabele- cendo metas para a criação de uma cooperativa (CARVALHO, 2011; MENEZES, 2005).

Em 1844 a cooperativa estabelecida ficou conhecida como Probos de Rochdale a qual foi responsável pelos princípios morais que são considerados até hoje como base do cooperativismo autêntico (CARVALHO, 2011; MENEZES, 2005).

Mais recentemente, em novembro de 1995, as ideias originais foram adaptadas no XXXI Congresso da Associação Cooperativa Internacional (ACI), realizado em Manchester, Inglaterra. Entre os sete princípios cooperativos definidos, a intercooperação é um dos que podem agregar para o sistema, pois visa estimular as cooperativas a trabalharem em conjunto.

A intercooperação, após a formação da cooperativa é considerada passo chave para as cooperativas se organizarem e contribuírem entre si e também com empresas do mercado e tem como objetivo favorecer o negócio da cooperativa em prol dos associados (MDIC, 2015).

As organizações, em geral, não detêm todas as competências necessárias para o desenvolvimento das suas atividades estratégicas. Por isso, a colaboração de parceiros pode ser uma opção para complementar competências. A estratégia de cooperação, até mesmo entre empresas diretamente concorrentes é, em alguns casos, adotada e pode facilitar à empresa o acesso a novos mercados, além do desenvolvimento de novos produtos e serviços de forma conjunta. Os mais diversos tipos de relacionamentos surgem para buscar atender algum tipo de necessidade ou problema das organizações envolvidas, e são estes problemas que determinam as razões ou motivações para empreender este ou aquele relacionamento.

Entretanto, cooperativas persistem atuando individualmente no mercado. Há casos de concorrência acirrada no ramo agropecuário, onde cooperativas invadem á área de atuação de outras organizações em busca de novos associados. Comportamento observado também em sistemas de intercooperação do ramo de crédito, por meio da abertura de unidades em localidades onde já existem sistemas semelhantes.

Com as cooperativas concorrendo entre si, fica exposta uma fragilidade no sistema cooperativo e o princípio da intercooperação não é praticado, criando uma dúvida central dos motivos das cooperativas 
não seguirem o princípio que mais se assemelha ao próprio cooperativismo.

Considerando estes aspectos, o presente estudo consiste em identificar as barreiras e desafios que impedem maior intercooperação entre cooperativas e apresentar exemplos de intercooperação entre cooperativas.

\section{Revisão de literatura}

\subsection{Princípios cooperativistas}

Com a formação da chamada mãe do cooperativismo ou Cooperativa de Rochdale, surgiram também os norteadores do cooperativismo da primeira cooperativa que definiam como princípio os seguintes valores: a) a sociedade seria governada democraticamente; b) cada sócio disponha de um voto; c) a sociedade seria aberta a quem dela quisesse participar, desde que ingressasse com uma cota capital mínima e igual para todos; d) qualquer dinheiro a mais investido na cooperativa seria remunerado por uma taxa de juros, mas não daria ao seu possuidor qualquer direito adicional de decisão; e) tudo que sobrasse das receitas deduzidas todas as despesas, inclusive juros, seria distribuído entre os sócios em proporção às compras que fizesse na cooperativa; f) todas as vendas seriam à vista e os produtos vendidos seriam puros e de boa qualidade; g) a sociedade deveria promover a educação dos sócios nos princípios do cooperativismo; $h$ ) a sociedade seria neutra política e religiosamente (MANICA E SCHMIDT, 2012, RIQUE, 2014).

No ano de 1995, em Manchester, na Inglaterra, no XXXI Congresso da Associação Cooperativa Internacional (ACI), os princípios cooperativos foram ajustados, e foram formulados os sete princípios cooperativos que são os atuais norteadores do sistema, conforme Manica e Schmidt (2012) descrevem:

$1^{\circ}$ Adesão livre e voluntária: São organizações abertas a todos que queiram e estão aptos a participar desde que tenham condições de assumir responsabilidades como associados, sem discriminação racial, religiosa, política, social e de sexo.

$2^{\circ}$ Gestão democrática pelos cooperados: Os associados participam ativamente na formulação de políticas e na tomada de decisão da cooperativa.

$3^{\circ}$ Participação econômica dos cooperados: Os cooperados participam economicamente da cooperati- va e suas sobras são divididas conforme as operações realizadas.

$4^{\circ}$ Autonomia e independência: Os negócios devem ser geridos de forma autônoma e independente, sem a interferência de governos ou qualquer entidade, pois os associados são os únicos que podem decidir pela cooperativa.

$5^{\circ}$ Educação, formação e informação: As cooperativas promovem a educação dos seus cooperados e informam o público em geral sobre os benefícios do cooperativismo.

$6^{\circ}$ Intercooperação: As cooperativas devem trabalhar em conjunto, por intermédio de estruturas locais, regionais, nacionais e internacionais.

$7^{\circ}$ Interesse pela comunidade: Através de suas ações as cooperativas trabalham para o desenvolvimento sustentável de suas comunidades.

\subsection{Intercooperação - redes}

A intercooperação é um dos principais caminhos para o fortalecimento do cooperativismo e uma das tendências desse cooperativismo contemporâneo é a formação de redes cooperativas, que tratam a intercooperação como ação estratégica para o futuro do negócio (GRANDE, 2015).

Um dos maiores exemplos da formação de redes é a Corporação Cooperativa Mondragón, que é formada por um complexo de cooperativas de produção industrial e serviços comerciais com um banco cooperativo, uma cooperativa de seguro social, uma universidade e diversas cooperativas focadas no desenvolvimento de tecnologias (BARBOSA, 2007).

O conceito de rede é bem difundido no mercado tanto em cooperativas, como também em empresas privadas que se unem em associativismo com a finalidade de ganho em comum através da união de esforços. Um desafio das redes é assegurar que as empresas da rede contribuam para o aumento dos recursos da rede e da eficácia, não importando quais partes são apropriadas por cada empresa (SYDOW; WINDELER, 1998). Braga (2010) comparou duas associações de produção de carne e concluiu que o sucesso da rede está na existência de objetivos em comum, no relacionamento e fluxo de informação e na geração de comprometimento dos membros em longo prazo. Portanto, neste contexto, Braga (2010), concluiu que a formulação clara dos objetivos, contribui para homogeneidade do processo e

RGC, Santa Maria, v.2, n.4, Págs. 45-58, jul./dez. 2015 
que quanto maior o compartilhamento de informação menor será o atrito e melhor a sintonia entre os membros.

As redes podem ser um modelo eficiente de intercooperação e um destes casos é o programa de excelência em gestão de rede de desenvolvimento integrado (RDI), criado pela Ocesp e Sescoop/ SP em parceria com o departamento de Cooperativismo e Associativismo, formado por 19 cooperativas do ramo agropecuário do Estado de São Paulo no ano de 2010. Os desafios são grandes, pois segundo um grupo de gestores as cooperativas possuem individualidades que precisam ser respeitadas, demonstrando que não estão tão abertas o quanto seria necessário. Em outro sentido, há gestores com visão de aproveitar as similaridades entre as cooperativas. E também existe uma corrente que entende que o processo de intercooperação pode demorar algum tempo para amadurecer (AGROANALYSIS, 2013).

Jerônimo et al., (2005), realizaram uma pesquisa em sete cooperativas de médio a grande porte do meio agropecuário localizadas geograficamente próximas no estado do Rio Grande do Sul que intercooperavam em rede nos formatos vertical e horizontal por meio do recebimento de produtos agropecuários dos associados, industrialização destes produtos e na distribuição e comercialização dos insumos agropecuários. A principal finalidade da intercooperação era voltada a obter ganhos em escala e consequentemente maior vantagem competitiva.

Os mecanismos de coordenação eram informais e facilitados pelos membros da rede, sendo que em poucos casos eram utilizados contratos formais para que se dividisse o resultado dos negócios realizados em conjunto. As decisões eram tomadas em conjunto, onde os membros se reuniam mensalmente para discutir assuntos pertinentes ao negócio (JERÔNIMO et al., 2005).

De acordo com Jerônimo et al., (2005), a confiança era um dos principais pontos positivo da intercooperação, onde se repudiava comportamentos oportunistas e apesar de existir diferença de tamanho entre cooperativas, todas eram tratadas de maneira igualitária.

A coordenação era realizada pelas próprias cooperativas sendo feita em forma de rodízio, ou seja, não foi criada uma empresa cooperativa para gerir o negócio, pois se julgou desnecessário (JERÔNIMO et al., 2005).
A rede trouxe como vantagem o ganho em escala em vários setores das cooperativas envolvidas, porém, segundo Jerônimo et al., (2005), as cooperativas consideraram como desvantagem a perda de propriedade individual da informação que no caso deveria ser compartilhada com os membros.

Dutra (2010) avaliou a rede de cooperativas de agricultores familiares da cadeia produtiva do leite da Região das Missões, Noroeste Colonial e Celeiro do Rio Grande do Sul (Rede Dalacto). Esta apresentava como objetivo geral o fortalecimento da bacia leiteira formada pelas cooperativas daquela região, das quais os cooperados de pequeno porte enfrentavam problemas de falta de assistência técnica, dependência excessiva das agroindústrias e limitações de produção devido à reduzida área das propriedades. Neste caso a rede representou a unificação destes associados, fortalecendo todos em um só negócio e proporcionando melhorias na qualidade de vida dos cooperados.

Os principais desafios da Rede Dalacto, estavam no número excessivo de atores que podem interferir nas negociações muitas vezes de forma prejudicial, na demora na tomada de decisão pelos conflitos ligados a interesses, no baixo nível de capacitação administrativa dos membros dirigentes das cooperativas, na disputa por recursos de cada membro, ocorrendo situações onde eram analisados apenas problemas locais, não se atentado aos problemas do território da rede como um todo. Outros fatores negativos constatados foram a baixa integração dos cooperados, a fragilidade do vínculo entre as cooperativas, a constante troca de diretoria das cooperativas e por fim a grande área de atuação que dificultava o deslocamento e a definição das prioridades locais (DUTRA, 2010).

\subsection{Intercooperação em redes - centrais}

As centrais de cooperativas são exemplos de intercooperação. Atualmente no Brasil há diversos exemplos, entre estas a Coonagro com 17 cooperativas e 61 mil associados, a Centro Leite com 15 cooperativas e 4,3 mil associados, a CCGL com 37 cooperativas e 162 mil associados (BRASIL COOPERATIVO, 2016). Os pesquisadores Oliveira e Palma (2009) estudaram o caso da Central das Cooperativas Agropecuárias do Nordeste do Rio Grande do Sul Ltda. (CCN), que conta com a participação de quinze cooperativas agropecuárias e tem como 
sede a cidade de Lagoa Vermelha. O objetivo desta central é potencializar os negócios em conjunto das cooperativas filiadas, visando ganhos de competitividade de mercado e evitando a invasão da área de atuação das cooperativas filiadas. Outras ações envolvem a qualificação dos profissionais que atuam nas cooperativas filiadas, pela promoção de formação continuada e troca de experiências, ou seja, a central tem como missão "promover a intercooperação e potencializar negócios conjuntos das filiadas, através da ética, do profissionalismo e do respeito à natureza".

Conforme Oliveira e Palma (2009), a CCN promovia ações conjuntas de armazenagem, transporte, comercialização, exportação e importação. O planejamento estratégico, os controles contábeis, os procedimentos padronizados e os projetos de capacitação também eram realizados de forma integrada. A Central agregava produtos de várias cooperativas filiadas, formando lotes maiores e buscando melhores preços. Com isto, no futuro, busca-se a ampliação dos negócios no mercado internacional principalmente no mercado de soja. No processo de compra se apresenta como projeto futuro a realização de compras com volumes maiores de produtos, com a finalidade de redução de custos, porém devido a diferenças culturais e compromissos diferentes entre cooperativas e fornecedores, este processo ainda não estava sendo realizado perdendo-se a oportunidade de realizar a barganha na compra de insumos, como adubos e defensivos químicos.

Um fator positivo do caso $\mathrm{CCN}$, de acordo com Oliveira e Palma (2009), era a retomada de credibilidade do sistema cooperativo, porém as dificuldades para o trabalho integrado neste arranjo estavam nas diferenças culturais existentes em cada cooperativa. Há de se considerar que as cooperativas agropecuárias foram constituídas cada uma em sua individualidade e já estão habituadas a operarem de forma singular e isto representa um fator de resistência para o relacionamento entre as cooperativas.

Galerani (2003) abordou um caso no ramo agropecuário que realizaram intercooperação por direcionamento e não por vontade própria. As organizações em questão foram a Cativa, uma cooperativa Singular e a Confepar uma central de cooperativas. A Cativa possuía na época problemas financeiros e a Confepar não recebia matéria prima suficiente para atender sua demanda, pois as cooperativas as- sociadas à central desviavam a produção para outros mercados devido a vantagens individuais.

A ação de integração foi uma exigência da Ocepar para liberar um recurso via Recoop (Plano de Revitalização) a Cativa. O acordo estabelecido determinava que a Cativa deixaria de processar o leite centralizando seu trabalho no campo onde receberia o leite repassando a Central Confepar para a industrialização. Neste mesmo período outras cooperativas também enfrentaram problemas e a Confepar foi reestruturada surgindo assim a Nova Confepar, uma central que tinha por objetivo a industrialização do leite recebido das cooperativas singulares (GALERANI, 2003).

A principal vantagem da Central considerada estava no fim da concorrência entre as cooperativas e no fim da inadimplência, já que as vendas ficavam concentradas na central, visando redução de custo e ganho em escala (GALERANI, 2003).

As dificuldades principais foram observadas na fase de articulação da central, onde predominava como objeção: a) interesses diferentes entre cooperativas; b) a remuneração ou não pelo uso do direito da marca das associadas; c) chegar a um acordo quanto à forma de remunerar pela matéria- prima de cada cooperativa; d) definição do custo benefício de se unir a central; e) decisão do fechamento das indústrias próprias; f) incorporação a uma central que já atuava na região; g) temor por parte dos associados referente ao desaparecimento de sua cooperativa; h) temor de alguns dirigentes com a diminuição de cargos; i) dificuldades referentes à situação financeira de algumas cooperativas, pois se temia a restrição de crédito. E um problema pósimplementação da Central estava no preço pago ao produtor já que a região de atuação era extensa e a isonomia gerava perdas de competitividade onde o preço praticado pelo mercado era superior ao pago pela cooperativa. Esta situação ocasionava a perda de matéria-prima para empresas mercantis (GALERANI, 2003).

\subsection{Intercooperação em redes - consórcios}

Outro exemplo de Intercooperação é o consórcio entre cooperativas. De acordo com Neto e Gomes (2010), este sistema tem por objetivo incrementar o poder de barganha no mercado, porém está modalidade não pode constituir personalidade jurídica própria, sendo que cada cooperativa consorciada

RGC, Santa Maria, v.2, n.4, Págs. 45-58, jul./dez. 2015 
deve responder por suas responsabilidades conforme acordado. Uma cooperativa é designada líder e será responsável pela escrituração contábil e a guarda de documentos.

A integração através de consórcio é bastante usada no ramo de cooperativas agropecuárias, pois tem como características a flexibilidade, a preservação de identidade e não envolve criação de novas pessoas jurídicas. Trata-se de uma união contratual entre cooperativas, beneficiadoras que têm como finalidade a ação conjunta na comercialização, aquisição de insumos e distribuição de produtos, permitindo ganhos em escala, redução de custos e aumento da competitividade (MDIC, 2015).

Neto e Gomes (2010) abordam o exemplo de dois consórcios entre cooperativas, o Consórcio Cooperativo Agropecuário Brasileiro (CCAB), fundado em 2006, formado por 14 cooperativas agropecuárias dos estados de SC, MT, MG e GO e o Consorcio Nacional Agroindustrial (COONAGRO), criado em setembro de 2008 por 19 cooperativas agropecuárias do Paraná. Ambos os consórcios tinham por finalidade a compra de defensivos químicos a preços e prazos mais competitivos, gerando impactos positivos nos resultados das cooperativas participantes, pois as mesmas elevavam suas margens para competir no mercado. Segundo Neto e Gomes (2010), a CCAB cresceu e comercializa produtos de sua marca e possuía projetos para expandir sua área de atuação. Por outro lado, a COONAGRO optou em transformar-se em uma central, pois enfrentava dificuldades de autonomia contábil para importar seus produtos, entretanto os objetivos foram mantidos. Outra área de atuação almejada era a de comercialização de commodities.

\subsection{Intercooperação - ramo agropecuário}

O cooperativismo agropecuário conta com mais de 1561 cooperativas, 1 milhão de associados, $48 \%$ da participação do total da agropecuária nacional, $21 \%$ da capacidade de armazenagem do país e $76 \%$ dos pequenos agricultores reconhecidos pelo Ministério do Desenvolvimento Agrário (MDA) são associados a uma cooperativa do sistema da Organização das Cooperativas do Brasil (OCB). Estas cooperativas possuem como principais objetivos a prestação de serviços e acesso à tecnologia aos associados, agregação de valor e atuação eficiente nas cadeias produtivas agropecuárias, economias de escala nos processos de compra e venda e o acesso a mercados (BRASIL COOPERATIVO, 2016, OCB SESCOOP, 2016).

Entretanto, é um dos ramos do cooperativismo que mais enfrentam dificuldades de implementar a intercooperação. Segundo Lago (2009) a falta de intercooperação entre cooperativas do ramo agropecuário é agravada devido às recorrentes crises financeiras por parte de algumas cooperativas. Portanto, este fator vem sendo o desafio a ser resolvido na busca da consolidação do relacionamento. Neste contexto, Lago (2009) explica que as razões de formar o relacionamento da intercooperação estão no ganho de escala, agregando valor e acessando a mercados com poder de barganha, com redução de custos e acesso a informações, inovações e estabilidade perante o ambiente econômico.

Lago (2009) condiciona à gestão profissional aliada a liderança, o controle, a clareza da doutrina, o comprometimento, a transparência, a eliminação de vaidades, o planejamento, a comunicação, a confiança e a independência como condições para o desenvolvimento dos sistemas de intercooperação. As invasões de áreas entre cooperativas e as recorrentes crises também são fatores condicionantes que afetam o processo de intercooperação (LAGO, 2009).

De acordo com Lago (2009), as cooperativas temem a perda de autonomia e o mesmo questiona se esta autonomia é de interesse dos associados, já que várias cooperativas agropecuárias enfrentam crises por não se abrirem. Por conseguinte, a vaidade é outro problema, já que muitos gestores temem perder seus postos de trabalho, ao passo que o não fortalecimento da cooperativa é o que pode promover uma total perda de autonomia. Ainda neste contexto, Lago (2009), destaca que as cooperativas não sabem quando podem confiar nas outras, visto que as cooperativas que estão em crise tendem as esconder os seus problemas.

De acordo com uma pesquisa realizada em cooperativas do ramo Agropecuário do Paraná por Ricken et al., (2009), os fatores que dificultam a integração entre as cooperativas, estão na forma como os dirigentes levam o negócio, onde $80,43 \%$ dos entrevistados destacaram a forma de atuação das cooperativas com excesso de competição, predominância de concorrência, rivalidade regional, falta de união, desigualdade de tamanho e falta de capital conjunto. Silva et al., (2010), analisaram em seu 
estudo 16 cooperativas que produzem vinho e buscou entender o modelo de negociação entre as cooperativas deste ramo. Foi concluído que o relacionamento entre cooperativas não garante automaticamente a intercooperação, pois os negociadores não estão dispostos a abrir mão dos resultados independentemente de quem for o parceiro comercial.

Diante das diferenças culturais, produtivas, financeiras, regionais e invasões da área de atuação entre si, as cooperativas criam um ambiente de revolta e competitividade, o que dificulta o processo de intercooperação. Neste contexto, Lago (2009) elenca estratégias que poderiam colaborar para desenvolver o cooperativismo no meio agropecuário, entre eles o fortalecimento de uma entidade cooperativa, com a finalidade de criar mecanismos de intervenção em cooperativas com problemas financeiros e de gestão, acompanhando, fiscalizando e punindo as cooperativas que desrespeitassem as regras do sistema. Neste sentido o sistema buscaria também confrontar e unificar os procedimentos das cooperativas.

Por fim, Lago (2009) salienta que resolvendo os fatores da invasão de áreas entre cooperativas e as crises financeiras, outros fatores vão se ajustando, como por exemplo, a confiança, comprometimento, a transparência, interdependência, dentre outros.

\subsection{Intercooperação - ramo crédito}

O ramo do cooperativismo de crédito é um dos mais evoluídos no princípio da integração entre as cooperativas, sendo que conta com vários sistemas. Entre estes se pode citar Sicoob, Sicredi, Unicred, Cecred, Confesol e Uniprime. Segundo dados de junho de 2014, existiam no Brasil 1154 cooperativas de crédito, com 6.393.825 associados e mais de 4.500 pontos de atendimento, ocupando a $6^{\mathrm{a}}$ posição no ranking das maiores instituições financeiras com 2,71\% dos ativos financeiros do Brasil. Contudo, comparativamente a outros países o Brasil ocupa a $16^{\mathrm{a}}$ posição no ranking de maior expressão do cooperativismo financeiro, sendo que a $1^{\text {a }}$ colocação é ocupada pela França que possui mais de 23 milhões de associados. Em 2012, existiam no Brasil 250 cooperativas singulares que não possuíam nenhum vínculo com sistemas, com 387 pontos de atendimento e 550 mil associados (OCB SESCOOP, 2016; COOPERATIVSMO DE CREDITO, 2016).
Neste sentido, Goes (2011), fez uma comparação entre duas cooperativas de crédito, uma que se integrou a um sistema que ele denominou de exemplo "A" e outra que não se integrou em nenhum sistema, porém possui parceria com uma cooperativa agroindustrial e a corretora de seguro da própria cooperativa agroindustrial, a qual foi denominada de exemplo "B". De acordo com Goes (2011), a intercooperação sistêmica "B", esbarrava em questões culturais, políticas e pessoais dos gestores, os quais defendiam a autonomia da cooperativa. Porém tal postura inibia a atração de novos associados, principalmente os jovens, pois a cooperativa no que tangia a investimentos em tecnologia estava abaixo do necessário. Outro fator de risco, no caso "B" estava relacionado a atuação estritamente regional com foco de negócios centralizados em poucas empresas, o que poderia deixá-la inviável devido às constantes mudanças do cenário financeiro (GOES, 2011).

As ações individuais realizadas no caso " $\mathrm{B}$ " não resultavam em crescimento significativo quando comparado ao caso "A". Sendo que enquanto a estratégia de "B" para captar mais associados estava na proximidade e no atendimento de suas necessidades, fugia-se de uma gestão estratégica. Não estando integrado, o caso " $\mathrm{B}$ " ficava limitado a oferecer poucos serviços e perdia a competitividade comparativamente ao caso "A" (GOES, 2011).

Neste sentido, "A" melhorou seu desempenho, através de ganhos em escala, como em tecnologia, estrutura física e marketing. Neste contexto, Goes (2011) conclui que "A" mantém o foco no associado, mas não perdendo o foco no mercado e o mais importante buscando o crescimento de forma integrada no sistema ao mesmo tempo em que atua de forma muito forte regionalmente, através de intercooperação local com outras cooperativas de diferentes ramos.

\subsection{Intercooperação: entre ramos diferentes de cooperativas}

Atualmente, o cooperativismo é dividido em 13 ramos, entre eles: agropecuário, crédito, consumo, educação, especial, habitacional, infraestrutura, mineral, produção, saúde, trabalho, transporte e turismo e lazer. "As atuais denominações dos ramos foram aprovadas pelo Conselho Diretor da OCB, em 4 de maio de 1993. A divisão também facilita a

RGC, Santa Maria, v.2, n.4, Págs. 45-58, jul./dez. 2015 
organização vertical das cooperativas em confederações, federações e centrais". Em 2012, o Brasil contava com mais de 6.600 cooperativas com 11 milhões de associados (BRASIL COOPERATIVO 2016, OCB SESCOOP, 2016).

A intercooperação entre cooperativas de ramos diferentes é um meio de as cooperativas contribuírem umas com as outras sem os problemas de concorrência que ocorrem entre cooperativas do mesmo ramo. Neste sentido, Oliveira e Silva (2012), destacaram a importância da intercooperação no cooperativismo através de um estudo em cooperativas de crédito da Creditag e cooperativas de produção no estado de Rondônia. A Creditag é um sistema de cooperativas de crédito constituída e administrada por agricultores da agricultura familiar, articuladas com organizações sociais, que tem como missão fortalecer e estimular à produção por produtores familiares rurais. Outros meios de atuação envolvem promover à educação financeira com incentivo a poupança e ao crédito, visando ao desenvolvimento sustentável e solidário, para melhoria da qualidade de vida no meio rural.

$\mathrm{Na}$ entrevista percebeu-se que a integração trouxe como vantagem para as cooperativas: a) a junção das cooperativas de crédito e produção no mesmo sistema Creditag, padronizando a operacionalização, b) capital de giro mais acessível para cooperativas de produção, c) crédito consciente, d) melhoria da renda do cooperado, e) ajuda na superação de dificuldades, f) incentivo à agricultura familiar, g) atendimento igualitário e mais inclusivo, h) integração de pessoas, i) fortalecimentos das cooperativas e j) menos dependência de atravessadores (OLIVEIRA E SILVA, 2012). Os pontos negativos do caso se dão por conta da falta de conhecimento e de informação sobre a relação entre as cooperativas (OLIVEIRA E SILVA, 2012).

\section{Metodologia}

A metodologia adotada trata-se de uma pesquisa exploratória bibliográfica de análise qualitativa. Conforme Lakatos e Makoni (2009), a pesquisa bibliográfica, trata-se de um levantamento de bibliografia já lançada em forma de livros, revistas, publicações avulsas e imprensa escrita, com a finalidade de situar o autor sobre o que já foi escrito de determinado assunto. A análise qualitativa é aquela que trabalha com dados qualitativos, ou seja, com informações não expressas, estritamente, em números. Os métodos mais recomendados para este tipo de pesquisa são entrevistas abertas, observação participante, análise documental e estudos de caso. (DALFOVO et al., 2008).

Para a coleta de informação foi realizada uma pesquisa bibliográfica em artigos científicos, teses de doutorado e livros, que abordavam o assunto cooperativismo e mais precisamente o princípio da intercooperação em cooperativas brasileiras, tema desta pesquisa.

A análise dos resultados foi qualitativa e com o uso da técnica de análise de conteúdo, fazendo um cruzamento e um discernimento, considerando os pontos relevantes ao problema e aos objetivos propostos para este trabalho. Gil (2009) define a análise de conteúdo como um dos métodos mais clássicos. Este pode ser aplicado a qualquer comunicação escrita, por exemplo, matérias publicadas em jornais, revistas, poemas, discursos e entrevistas.

Sendo assim, foram analisados os modelos de intercooperação em redes, por meio de centrais e consórcios. Na sequência, foram buscados casos de intercooperação nos ramos agropecuário, crédito e entre cooperativas de ramos diferentes. $\mathrm{O}$ principal foco nos documentos pesquisados foi levantar os pontos que dificultam que a intercooperação seja amplamente difundida nas cooperativas.

\section{Resultados e discussão}

A pesquisa bibliográfica realizada possibilitou o levantamento de diversos fatores considerados barreiras para maior intercooperação. No Quadro 1, os fatores são apresentados ordenados por modelos de intercooperação e ramos de atividade do cooperativismo. 
Quadro 1: Panorama de fatores que impedem a intercooperação no sistema cooperativo conforme revisão de literatura.

\begin{tabular}{|c|c|c|}
\hline $\begin{array}{l}\text { Modelos e ramos de } \\
\text { intercooperação }\end{array}$ & Fatores que impedem a intercooperação & Referências \\
\hline Redes & $\begin{array}{l}\text { Falta de formalização do arranjo inter organizacional; } \\
\text { Falta de definição clara de objetivos; } \\
\text { Falta de compartilhamento de informação; } \\
\text { Número excessivo de atores; } \\
\text { Demora na tomada de decisão; } \\
\text { Baixo nível de capacitação administrativa dos membros dirigen- } \\
\text { tes; } \\
\text { Disputa por recursos de cada membro (individualismo); } \\
\text { Baixa integração dos cooperados (oportunismo); } \\
\text { Fragilidade do vínculo entre as cooperativas; } \\
\text { Constante troca de diretoria da cooperativa; } \\
\text { Grande área de atuação; }\end{array}$ & $\begin{array}{l}\text { (Jerônimo et al., } \\
2005) . \quad \text { (Braga, } \\
2010) \quad \text { (Agroa- } \\
\text { nalysis, 2013). } \\
\text { (Dutra, 2010). }\end{array}$ \\
\hline Centrais & $\begin{array}{l}\text { Diferenças culturais; } \\
\text { Compromissos distintos entre cooperativas e fornecedores (inte- } \\
\text { resses individuais); } \\
\text { Hábito de atuarem de forma individual; } \\
\text { Dificuldades quanto ao uso do direito da marca das associadas; } \\
\text { Dificuldades quanto à forma de remunerar pela matéria-prima de } \\
\text { cada cooperativa; } \\
\text { Custo benefício de se unir a central; } \\
\text { Fechamento das indústrias próprias; } \\
\text { Temor por parte dos associados referente ao desaparecimento de } \\
\text { sua cooperativa; } \\
\text { Temor de alguns dirigentes com a diminuição de cargos; } \\
\text { A situação financeira instável de alguma cooperativa; } \\
\text { Preço pago ao produtor pela mercadoria entregue não competiti- } \\
\text { vo; }\end{array}$ & $\begin{array}{l}\text { (Oliveira e Pal- } \\
\text { ma, 2009). (Ga- } \\
\text { lerani, 2013). }\end{array}$ \\
\hline Consórcios & Dificuldade de autonomia contábil para importar seus produtos; & $\begin{array}{l}\text { (Neto e Gomes, } \\
\text { 2010). }\end{array}$ \\
\hline Ramo agrope & $\begin{array}{l}\text { Falta de confiança; } \\
\text { Invasões de áreas entre cooperativas e as recorrentes crises; } \\
\text { Perda de autonomia; } \\
\text { Vaidade; } \\
\text { Excesso de competição; } \\
\text { Rivalidade regional; } \\
\text { Falta de união; } \\
\text { Desigualdade de tamanho; } \\
\text { Falta de capital conjunto; } \\
\text { Não estão dispostos a abrir mão dos resultados independente- } \\
\text { mente de quem for o parceiro comercial; }\end{array}$ & $\begin{array}{l}\text { (Lago, 2009; } \\
\text { Ricken et al., } \\
\text { 2009; Silva et } \\
\text { al., 2010). }\end{array}$ \\
\hline Ramo crédito & $\begin{array}{l}\text { Questões culturais; } \\
\text { Questões políticas e pessoais dos gestores; } \\
\text { Mudança do cenário financeiro; }\end{array}$ & (Goes, 2011) \\
\hline $\begin{array}{l}\text { Intercooperação entre } \\
\text { diferentes ramos }\end{array}$ & $\begin{array}{l}\text { Falta de conhecimento e de informação sobre a relação entre as } \\
\text { cooperativas; }\end{array}$ & $\begin{array}{l}\text { (Oliveira e Silva, } \\
\text { 2012). }\end{array}$ \\
\hline
\end{tabular}


Os princípios cooperativos foram criados junto com a primeira cooperativa e são os norteadores de todas cooperativas. Estes princípios estão estabelecidos, portanto, entende-se que a atividade cooperativa passe pelo cumprimento destes. Assim, as cooperativas e seus agentes são desafiados a encontrar formas de cumprir estes princípios.

Verificou-se que existem várias formas das cooperativas intercooperar, sendo por rede, por centrais e consórcios e que a intercooperação pode ocorrer em cooperativas dos mais diversos ramos. A pesquisa apontou, principalmente, o ramo agropecuário e de crédito.

Em ambos os casos pesquisados, notou-se que alguns benefícios da intercooperação estão em potencializar os negócios em conjunto nas mais diferentes áreas com ganho de competitividade de mercado, qualificação profissional, com troca de experiências, com padronização de processos, com acesso a inovação e informação, com ações de marketing em conjunto e com melhora em sistemas tecnológicos. Porém, como fatores que podem impedir a intercooperação, destacam-se a falta de caráter formal de algumas redes, onde não se tem clareza dos objetivos em comum e não se compartilham as informações necessárias para que os negócios se efetivem. Braga (2010) define quatro fatores identificados por Ward (2002) para o sucesso das alianças verticais e um deles é a existência de objetivos em comum. "A formulação específica e clara de objetivos pode permitir aos participantes a forma mais precisa de combinar seus objetivos com os objetivos da aliança".

O número excessivo de membros em conjunto, a política democrática das cooperativas e a baixa capacitação dos membros diretivos gera atrasos na tomada de decisão, fazendo com que muitas cooperativas não se disponham a tal situação. Dutra (2010) explica que para uma maior agilidade na tomada de decisão "é importante que haja um planejamento participativo tanto nas cooperativas quanto na rede, facilitando o entendimento e alinhamento dos objetivos em comum".

$\mathrm{O}$ individualismo e o oportunismo fragilizam o vínculo entre as cooperativas, pois ao invés de elaborarem estratégias que favoreçam as ações coletivas, prevalece nestes casos à atuação local com brigas internas em favor de investir onde interessa a um só membro e não ao todo. Este fato pode ser entendido como resquício da baixa integração entre cooperados que só se unem em períodos que a situação é desfavorável, deixando de interagir nos momentos de resultados positivos.

Muitas redes possuem uma grande área de atuação e esta condição dificulta o trabalho. Dutra (2010) explica que "a área de abrangência é um problema, por exigir um deslocamento maior dos participantes que tem resistência em sair de suas localidades". Para promoção da rede as cooperativas necessitam que seus representantes se desloquem a grandes distâncias com finalidade de participar de eventos, bem como atuarem juntos aos seus associados. As particularidades de cada região dificultam que a cooperativa desperte o interesse de seus membros devido às diferenças culturais e até mesmos em relação a vantagens econômicofinanceiras. Um ponto a se destacar é que preços e custos de mercadorias variam de uma região para outra, trazendo desta forma falta de interesse do associado de participar da cooperativa e por consequência da cooperativa em participar da rede.

As diferenças culturais, geralmente, são impactantes na formação da rede, pois existe um tempo de adaptação e conhecimento necessário para que as redes se concretizem, porém as mudanças no quadro diretivo das cooperativas acarretam em novos argumentos e pensamentos, gerando mal estar entre os participantes que já possuíam um planejamento efetuado. Dutra (2010), explica que a troca de diretoria é comum, porém "deve ser previsto no regimento interno que ações programadas anteriormente devem ser mantidas sem interferência até que o novo representante participe de determinado número de reuniões ou por determinado período".

Está presente em alguns casos a crença que o individualismo representa uma chance de cooperativas serem melhores e mais competitivas, principalmente na cooperativas de maior porte. Estas, por vezes, conseguem vantajosas negociações com fornecedores. Por exemplo, melhores preços, maiores prazos para pagamento, agilidade na entrega de mercadorias, entre outros fatores. Entretanto, esta visão pode estar equivocada, pois em muitos casos não é de interesse dos fornecedores que as cooperativas trabalhem em conjunto. Geralmente, estas ações individuais desestabilizam as redes que em longo prazo trariam benefícios a todas as cooperativas. Dutra (2010) cita que os preços diferenciados 
podem abrir portas para o comportamento individualista, pois muitos membros só negociariam com a rede nos produtos que conseguissem adquirir a um preço menor e neste contexto o autor cita que "os principais fornecedores da rede podem formar um oligopólio que naturalmente não tem interesse que seus clientes se organizem para melhorar seu poder de negociação". Além disso, podem ser identificadas tentativas de alguns fornecedores de desestabilizar a rede por meio de uma política comercial diferenciada entre os associados desta mesma rede.

Muitas cooperativas possuem estrutura física, condição financeira e marca forte, e devido a isto são bastante resistentes em intercooperar, pois temem que esta união promova enfraquecimento da marca. Nestes casos unir-se com cooperativas frágeis economicamente não geraria competitividade necessária para crescer e sim, na visão dos gestores, resultaria em uma união com uma organização que veem como um concorrente que não administra bem seus negócios e que por consequência enfraqueceria a Cooperativa. Lago (2009) cita que devido às recorrentes crises financeiras que algumas cooperativas vêm enfrentando, esta situação vem dificultando o desenvolvimento da intercooperação, pois cada cooperativa não sabe o quanto pode confiar em sua coirmã, sem que venha a ter prejuízos em um eventual problema de uma das cooperativas.

No sistema cooperativo o ramo agropecuário apresenta baixa taxa de intercooperação. Segundo Ricken et al., (2009), a forma de atuação, onde predomina a concorrência, a competição, a rivalidade regional, a falta de união e desigualdade de tamanho dificultam maior intercooperação em cooperativas do ramo agropecuário.

Nesta condição há cooperativas que, acreditando serem melhores, invadem a áreas de atuação das outras agindo com uma empresa mercantil comum, gerando disputas por preço e por associados que mais parecem clientes. Com maior sentimento de pertencer a cooperativa os associados seriam menos propensos a negociar fora da cooperativa por alguns benefícios. Porém no ramo agropecuário isto acontece de forma recorrente no período de comercialização de grãos. Lago (2009) destaca que "as frequentes invasões de áreas de atuação das cooperativas entre si, criam um ambiente de revolta e competitividade acirrada que impede qualquer iniciativa de intercooperação".
Estas cooperativas temem a perda de autonomia, mas o contexto indica que esta já se apresenta reduzida. Quando negociam com seus associados pouco interessa o relacionamento e sim quem propõe a melhor condição, sendo que em alguns casos um mesmo individuo é sócio de mais de uma cooperativa e especula preços em todas.

A intercooperação traria muito mais autonomia, pois com todas participando em conjunto através de redes, centrais ou consórcios, seria possível maior estabilidade das cooperativas, entregando resultado ao negócio e por fim a seus donos. Entretanto nem todas estão dispostas a abrir mão da competição independentemente de quem for o parceiro comercial. Neste contexto Lago (2009), cita como exemplo "as disputas por espaço e vaidades entre dirigentes, dado o receio de perda de poder ou posto de trabalho, o que reflete uma enorme miopia, ao passo que o não fortalecimento da cooperativa é que pode representar a perda de autonomia".

O ramo de crédito é um dos mais evoluídos em relação à intercooperação, no entanto ainda existem razões culturais que impedem a intercooperação, pois muitas cooperativas acreditam que a intercooperação trará perda de autonomia e até mesmo a perda de identidade da cooperativa. Segundo Lago (2009), as diferenças financeiras, culturais, produtivas, profissionais, regionais, entre outras são fatores que impedem a intercooperação. Porém devido a fatores do cenário financeiro as cooperativas deste ramo estão mais motivadas a intercooperar, pois precisam de liquidez e oferecer serviços que necessitam de alta escala. Somado a isso, devem seguir determinações do Banco Central que atuando isoladamente, muitas vezes, tornariam as cooperativas inviáveis.

A intercooperação entre cooperativas de ramos diferentes ainda é bastante frágil basta verificar que tipo de empresas, na maioria dos casos, são contratadas para prestar serviços de limpeza e segurança nas cooperativas de crédito e produção. O principal fator que impende a intercooperação neste caso é a falta de relação entre os ramos do cooperativismo, promovendo situação de vantagem competitiva para ambas as partes.

\section{Considerações finais}

O cooperativismo é um sistema de ajuda mutua entre classes que possuem interesses semelhantes e 
que são baseados por princípios que norteiam seus valores. Porém alguns destes princípios não são seguidos pelo sistema, o que pode ocasionar desvios nos valores cooperativistas. A intercooperação é um principio que pode agregar para o sistema cooperativista, pois trabalhando juntas as cooperativas contribuem entre si gerando ganhos em escala, qualificação profissional, padronização de processos, entre outras vantagens. Entretanto, este princípio ainda é pouco seguido nas cooperativas e para tanto se buscou entender os motivos das resistências das cooperativas em intercooperar.

A formação de redes, que podem ser por consórcios, centrais, entre outros métodos, são exemplos de como a intercooperação pode ser colocada em prática.

Entre as principais barreiras e desafios que impendem maior intercooperação entre as cooperativas estão às diferenças culturais, o medo da perda de autonomia, a vaidade, a falta de confiança, a competição entre organizações e as diferenças no modo de gestores avaliarem e agirem com a intercooperação. Pois muitos arranjos de intercooperação não são, adequadamente, formalizados, o que gera demora na tomada de decisão. A inadequada capacitação de gestores pode acarretar em dificuldades financeiras para as cooperativas e consequentemente dificultar aproximações entre cooperativas. Apesar das cooperativas terem na sua essência o princípio de cooperar, o individualismo e o oportunismo ainda está presente, principalmente nas centrais onde cooperativas apenas cooperam em momentos vantajosos para si ou em momentos que a cooperativa está muito frágil economicamente.

A grande área de atuação, a desigualdade de tamanho, a perda da marca por parte dos associados e a perda dos cargos pelos gestores ainda são limitadores para que haja intercooperação, pois muitos gestores e associados temem a perda de autonomia e perda de poder na tomada de decisão. Ocorrendo uma discussão complexa de quem ficará com o poder decisório.

O conjunto de fatores considerado como barreira a ocorrência de intercooperação plena nas cooperativas foi exposto e analisado. Entretanto este cenário desafiador só pode ser alterado com uma mudança cultural, onde as organizações percebam que são cooperativas e que não tem sentido agirem de forma individual competindo umas com as outras por uma fatia de mercado. Seguindo a definição do modelo cooperativista a finalidade não é o lucro e sim a resolução de problemas sociais através de resultados positivos para a comunidade. Entende-se como um dos meios de se obter esta mudança a educação cooperativa.

Para um próximo estudo pode-se analisar o quanto o porte da cooperativa pode influenciar na intenção e efetivação da intercooperação. Nos casos estudados as cooperativas eram, em sua maioria, de grande porte e notou-se que enfrentavam dificuldades em intercooperar.

\section{Referências}

AGROANALYSIS. Cooperativismo paulista aposta na intercooperação. Set. 2013. Disponível em:< http://www.agroanalysis.com.br/9/2013/conteud o-especial/cooperativismo-paulista-aposta-naintercooperacao-especial-cooperativismo\#>. Acesso em: 14 de Outubro de 2015.

BARBOSA, Leticia Cristina Bizaro. Cooperativas articuladas em rede e o mercado: o sucesso das estratégias da Cooperação Cooperativa Mondragón. Revista espaço acadêmico, n 70, ano VI, março 2007. Disponível em: <http://www.espacoacademico.com.br/070/70bar bosa.htm>. Acesso em: 24 de Janeiro de 2016.

BRAGA, Marcelo Jose. Redes, alianças estratégicas e intercooperação: O caso da cadeia produtiva da carne bovina. Revista Brasileira de Zootecnia, v39, p.11-16, 2010 (supl. Especial). Disponível em: <http://www.scielo.br/pdf/rbz/v39ssppe/>. Acesso em 14 de Outubro de 2015.

BRASIL COOPERATIVO, Apresentação Institucional Sistema Cooperativista. 2011. Disponível em: <http://www.brasilcooperativo.coop.br/>. Acesso em 24 de Janeiro de 2016.

CARVALHO, Adriano Dias de. O Cooperativismo sob a ótica da gestão estratégica global. São Paulo: Baraúna, 2011.

DALFOVO, Michael Samir; LANA, Rogério Adilson; SILVEIRA, Amélia. Métodos quantitativos e qualitativos: um resgate teórico. Revista Interdisciplinar Científica Aplicada, Blumenau, v.2, n.4, p.01-13, Sem II. 2008. Disponível em: 
<http://www.unisc.com.br>. Acesso em: $21 \mathrm{de}$ Abril de 2015.

DUTRA, Jose Carlos Nascimento. A intercooperação como processo de desenvolvimento: Um caso de cooperativas articuladas em rede. Ijui: $2010 . \quad$ Disponível em: <http://bibliodigital.unijui.edu.br:8080/xmlui/bit stre-

am/handle/123456789/1188/Jose\%20Carlos\%20 Nascimento\%20Dutra.pdf? sequence $=1>$. Acesso em 14 de Outubro de 2015.

GALERANI, Jair. Formação, estruturação e implementação de aliança estratégica entre empresas cooperativas. RAE Eletrônica, v.2, n.1, jan-jun $2003 . \quad$ Disponível em: <http://rae.fgv.br/sites/rae.fgv.br/files/artigos/10. 1590_S1676-56482003000100014.pdf> Acesso em: 14 de Outubro de 2015.

GAWLAK, Albino; RATZKE, Fabiane. Cooperativismo: Primeiras lições. $3^{\mathrm{a}}$. Ed. Brasília: Sescoop, 2007.

GIL, Antonio Carlos. Estudo de Caso. São Paulo: Atlas, 2009.

GRANDE, Edivaldo Dei. Intercooperação: gerando valor para as cooperativas. Disponível em: $<$ http://app2.unimedseguros.com.br/encontros cooperativos/artigo.asp?id=4>. Acesso em 05 de maio de 2015.

GOES, Milton Cesar. Cooperação e Performance Econômica: O Sicredi (Brasil). Vila Real: 2011. Disponível em:<http://repositorio.utad.ptbitstream 10348325 41msc_mcgoes.pdf $>$. Acesso em 05 de maio de 2015.

MINISTERIO DO DESENVOLVIMENTO, INDÚSTRIA E COMERCIO EXTERIOR (MDIC). Intercooperação, Conceitos e Definições. Disponível em: $<$ http://www.mdic.gov.br/sistemas_web/aprende $\mathrm{x} /$ cooperativismo/index/conteudo/id/317> Acesso em: 15 de maio de 2015
JERÔNIMO, Fatima Benhcker; PEDROZO, Eugênio Ávila; FENSTERSEIFER, Jaime Evaldo; SILVA, Tânia Nunes. Rede de Cooperação e Mecanismos de Coordenação: A Experiência da Rede Formada por Sete Sociedades Cooperativas no Rio Grande do Sul. Ribeirão Preto: 2005. Disponível em: >http://www.sober.org.brpalestra2984.pdf>. Acesso em 15 de agosto de 2015.

LAGO, Adriano. Fatores Condicionantes do Desenvolvimento de Relacionamentos Intercooperativos no Cooperativismo Agropecuário. Porto Alegre: $2009 . \quad$ Disponível em:<http://www.lume.ufrgs.brbitstreamhandle10 18318439000729139.pdfsequence $=1>$. Acesso em 05 de maio de 2015.

MANICA, Sergio Afonso; SCHMIDT, Carmen Elizabeth Finkler. O confronto ideológico do Cooperativismo na Economia de mercado. Revista Reflexão Cooperativista, Porto Alegre, v.1, n.1, p. 05-24, agosto de 2012.

SILVA, Tânia Nunes; GONÇALVES, Wilson Magela; DIAS, Marcelo Fernandes Pacheco. Intercooperação e Estilos de Negociação em Cooperativas Produtoras de Vinho no Rio Grande do Sul. 2010. Disponível em: <file:///C:/Documents\%20and\%20Settings/usuario/ Meus\%20documentos/Downloads/Silva_Gon\% C3\%A7alves_Dias_2010_Intercooperacao-eestilos-de-n_3706\%20(1).pdf.> Acesso em: 15 de agosto de 2015.

MARCONI, Marina Andrade; LAKATOS, Eva Maria. Metodologia do Trabalho Científico. São Paulo: Atlas, 2009.

MENEZES, Antonio. Nos Rumos do Cooperativismo. Brasília: Stilo, 2005.

NETO, Sigismundo Bialoskorski; GOMES, Acad Caio Botelho: Um Ensaio Sobre os Desafios da Intercooperação entre Cooperativas Agropecuárias no Brasil. I Encontro Brasileiro de Pesquisadores em Cooperativismo (EBPC). Brasília: 2010. Disponível em: <http://www.fearp.usp.brcooperativismo40.pdf>. Acesso em: 05 de maio de 2015. 
NOWAK, Martin Andreas. Five rules for the evolution of cooperation. Science, Washington, v. 314, n. 5805, p. 1560-1563. 2006.

OCB SESCOOP. Ramos do cooperativismo. Disponível em: <http://www.ocb.org.br/site/ramos/index.asp>. Acesso em 24 de Janeiro de 2016.

OLIVEIRA, Lessandra Medeiros; PALMA, Lisiane Celia. Os Desafios da Intercooperação: O Caso da Central de Cooperativas- CMN. Sociedade Brasileira de Economia, Administração e Sociologia Rural. Porto Alegre: 26 a 29 de julho de 2009. Disponível em: < http://www.sober.org.brpalestra2984.pdf>. Acesso em: 05 de maio de 2015.

OLIVEIRA, Nilza Duarte Aleixo; SILVA, Tânia Nunes. Inovação Social e Tecnologias Sociais Sustentáveis em Relacionamentos Intercooperativos: Um Estudo Exploratório do Creditag- RO. Revista Administradores UFSM, V.5, N.2, P.277- 295, Mai. / Ago.2012.

OSTROM, Elinor. Collective action and the evolution of social norms. Journal of Economic Perspectives, v. 14, 137-158, 2000.

PENNISI, Elizabeth. How did cooperative behavior evolve? Science, Washington, v. 309, n. 5731, p. 93, July 2005.

RICKEN, José Roberto; TENÓRIO, Fernando Guilherme; KRONEMBERGER, Thais Soares. O Cooperativismo Agropecuário no Estado do Paraná: A Questão da Integração. Disponível em: $<$ http://www.fearp.usp.br/cooperativismo/25.pdf >. Acesso em: 05 Jan. 2015.

RIQUE, Mônica. Os Pioneiros de Rochdale e os Princípios do Cooperativismo. Disponível em: $<$ http://www.cooperativismopopular.com.br/brev e_hist_leia.php>. Acesso em: 03 Dez. 2014.

SMITH, Eric Alden. Human cooperation: perspectives from behavioral ecology. In: HAMMERSTEIN, P. (Org.). Genetic and cultural evolution of cooperation. London: Dahlem University Press. 2003. p.402-427.
SYDOW, Jörg; WINDELER, Arnold. Organizing and evaluating interfirm networks: a structurationist perspective on network processes and effectiveness. Organization Science, Vol. 9, $\mathrm{n}^{\circ}$. 3, May-June, 1998.

ZAMBERLAM, Jurandir; FRONCHETI, Alceu. Cooperação agrícola: melhoria econômica ou novo projeto de vida? Passo Fundo: Berthier. 1992. $136 \mathrm{p}$. 